\title{
Decrease in membrane fluidity and traction force induced by silica-coated magnetic nanoparticles
}

\author{
Tae Hwan Shin ${ }^{1 \dagger}$, Abdurazak Aman Ketebo ${ }^{2 \dagger}$, Da Yeon Lee 1 , Seungah Lee 3 , Seong Ho Kang 3 , Shaherin Basith', \\ Balachandran Manavalan', Do Hyeon Kwon ${ }^{4}$, Sungsu Park ${ }^{2^{*}}$ and Gwang Lee ${ }^{1,4^{*}}$ (D)
}

\begin{abstract}
Background: Nanoparticles are being increasingly used in biomedical applications owing to their unique physical and chemical properties and small size. However, their biophysical assessment and evaluation of side-effects remain challenging. We addressed this issue by investigating the effects of silica-coated magnetic nanoparticles containing rhodamine B isothiocyanate [MNPs@SiO ${ }_{2}$ (RITC)] on biophysical aspects, such as membrane fluidity and traction force of human embryonic kidney 293 (HEK293) cells. We further extended our understanding on the biophysical effects of nanoparticles on cells using a combination of metabolic profiling and transcriptomic network analysis.
\end{abstract}

Results: Overdose $(1.0 \mu \mathrm{g} / \mu \mathrm{L})$ treatment with MNPs@SiO $2(\mathrm{RITC})$ induced lipid peroxidation and decreased membrane fluidity in HEK293 cells. In addition, HEK293 cells were morphologically shrunk, and their aspect ratio was significantly decreased. We found that each traction force (measured in micropillar) was increased, thereby increasing the total traction force in MNPs@SiO $(\mathrm{RITC})$-treated HEK293 cells. Due to the reduction in membrane fluidity and elevation of traction force, the velocity of cell movement was also significantly decreased. Moreover, intracellular level of adenosine triphosphate (ATP) was also decreased in a dose-dependent manner upon treatment with MNPs@SiO 2 (RITC). To understand these biophysical changes in cells, we analysed the transcriptome and metabolic profiles and generated a metabotranscriptomics network, which revealed relationships among peroxidation of lipids, focal adhesion, cell movement, and related genes and metabolites. Furthermore, in silico prediction of the network showed increment in the peroxidation of lipids and suppression of focal adhesion and cell movement.

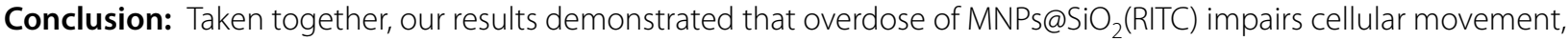
followed by changes in the biophysical properties of cells, thus highlighting the need for biophysical assessment of nanoparticle-induced side-effects.

Keywords: Cell movement, Membrane fluidity, Micropillar, Silica-coated magnetic nanoparticles, Traction force

*Correspondence: nanopark@skku.edu; glee@ajou.ac.kr

tTae Hwan Shin and Abdurazak Aman Ketebo contributed equally to this work

1 Department of Physiology, Ajou University School of Medicine, Suwon 16499, Republic of Korea

2 School of Mechanical Engineering, Sungkyunkwan University, Suwon 16419, Republic of Korea

Full list of author information is available at the end of the article

\section{Background}

The use of nanoparticles for diagnostic and therapeutic purposes has been rapidly increasing in medicine. However, as the small size of nanoparticles is known to enable their cellular entry and accumulation, this could potentially cause cellular dysfunction [1-4]. Moreover, compared with bulk materials, nanoparticles are known to be more reactive and owing to their higher surfaceto-volume ratio might exhibit more side-effects, such

c) The Author(s) 2021. This article is licensed under a Creative Commons Attribution 4.0 International License, which permits use, sharing, adaptation, distribution and reproduction in any medium or format, as long as you give appropriate credit to the original author(s) and the source, provide a link to the Creative Commons licence, and indicate if changes were made. The images or other third party material in this article are included in the article's Creative Commons licence, unless indicated otherwise in a credit line to the material. If material is not included in the article's Creative Commons licence and your intended use is not permitted by statutory regulation or exceeds the permitted use, you will need to obtain permission directly from the copyright holder. To view a copy of this licence, visit http://creativeco mmons.org/licenses/by/4.0/. The Creative Commons Public Domain Dedication waiver (http://creativecommons.org/publicdomain/ zero/1.0/) applies to the data made available in this article, unless otherwise stated in a credit line to the data. 
as the generation of reactive oxygen species (ROS) [57]. Nevertheless, our current knowledge regarding the effects of nanoparticles on specific physical and mechanobiological aspects of the cell remains insufficient due to limitations in the available analytical methods.

Magnetic nanoparticles (MNPs) have been commonly used as biosensors as well as diagnostic and delivery tools in biomedicine and biotechnology [8-10]. More specifically, several biocompatible materials, such as silica, polyethyleneimine, and chitosan have been used to coat nanomaterials to both reduce side-effects and confer beneficial properties on bare nanomaterials [11-17].

Among MNPs, silica-coated MNPs containing rhodamine B isothiocyanate [MNPs@SiO $2(\mathrm{RITC})]$, with layers of silica and a MNP core, are being used for separating and marking cells [13]. Based on traditional methods of evaluation of toxicity, such as the chromosome aberration test, haematoxylin and eosin staining, 3-(4,5-dimethylthiazol-2-yl)-2,5-diphenyltetrazolium bromide (MTT) test,

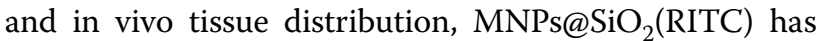
been reported to be nontoxic [18-22]. However, it was suggested that MNPs@SiO $\mathrm{S}_{2}(\mathrm{RITC})$ might exert biophysical side effects via the generation of ROS in cells $[4,21]$.

Briefly, ROS are known to oxidize membranous lipids as well as cytoskeleton proteins. In particular, ROS can oxidize polyunsaturated phospholipids, glycolipids, and cholesterol in the membrane [23], thereby reducing membrane fluidity and permeability [24, 25]. In addition, internalised nanoparticles have been shown to impair cytoskeleton proteins and interfere with focal adhesion kinase-mediated signalling [26]. With lamellipodia (branched actin filaments) and filopodia (extended finger-like protrusions), cell adhesion is known to occur due to the presence of focal adhesion (FA) complexes, with cell morphology being determined through the balance between adhesion and tension [27]. The involvement of adenosine triphosphate (ATP) in the movement of myosin over filamentous actin (F-actin) and in the polymerization of actin has suggested that cellular mechanics could be altered by ATP depletion [28]. In that regard, treatment with MNPs@SiO ${ }_{2}$ (RITC) has been reported to have caused metabolic changes in cells, including ATP depletion [21].

The submicron elastomeric pillar array is considered an excellent tool for measuring cellular force as the nanometric level of pillar deflection can be calculated by incorporating optical microscope imaging $[29,30]$. Furthermore, it can be used to analyse the initial contact of a cell with a substrate and has been reported to mimic continuous substrates of a specific rigidity [31]. Thus, the mechanobiological effects of nanoparticles on cells could be quantitatively studied by measuring the traction force using submicron elastomeric pillars [29, 31].

Assessment of potential side-effects of nanoparticles using classical methods is limited owing to delicate changes and complexities at the nano level. Thus, instead of focusing on targeted molecules, omics approaches, including genomics, transcriptomics, proteomics, and metabolomics, have been used in nanotoxicity studies [22]. However, restrictions in assessing the intricate signalling pathways and delicate events in cells and organisms still exist. For example, although transcriptomics can reflect enormous genotypic changes, it has been shown to be insufficient for understanding the actual phenotype [32, 33]. In contrast, in the case of metabolomics, which can constitute an endpoint feature of biological phenotypes [34, 35], no amplification methods are available for very low-abundance metabolites, and quantitative analysis of the targeted method might likely provide only a partial representation of the overall metabolism [36]. Accordingly, a combination of transcriptomics and metabolomics, termed "metabotranscriptomics", has been utilised for a more comprehensive analysis of cells and evaluation of nanotoxicity following treatment with nanoparticles $[4,21,22]$.

We have previously analysed the effects of MNPs@ $\mathrm{SiO}_{2}(\mathrm{RITC})$ on HEK293 cells $[4,21,37,38]$. In addition, HEK293 cells have also been extensively used in the study of nanoparticle-induced toxicity and in renal toxicity models $[39,40]$. In the present study, we analysed membrane fluidity, which is an important indicator of biophysical changes, including cell freshness

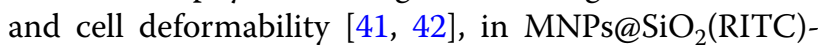
treated HEK293 cells using total internal reflection fluorescence microscopy (TIRFM). Moreover, we measured the changes in the traction force, which is known to directly reflect biophysical changes and has been highly correlated with changes in cell membrane in MNPs@SiO ${ }_{2}$ (RITC)-treated HEK293 cells. Thus, metabotranscriptomics-based biophysical assessment was performed to comprehensively evaluate MNPs@ $\mathrm{SiO}_{2}$ (RITC)-induced effects on HEK293 cells.

\section{Results}

\section{Characteristics of MNPs@SiO ${ }_{2}(\mathrm{RITC})$ and silica NPs}

Our generated MNPs@SiO 2 (RITC) nanoparticles consisted of an approximately 9-nm cobalt ferrite core $\left(\mathrm{CoFe}_{2} \mathrm{O}_{3}\right)$ chemically bonded to rhodamine isothiocyanate dye (RITC) and coated with a silica shell [13]. Moreover, silica nanoparticles, which are identical to the silica shell of MNPs@SiO 2 (RITC), have been shown to exhibit similar biological effects to those exhibited by MNPs@SiO 2 (RITC) [4, 20, 21]. The diameter of both 
MNPs@SiO ${ }_{2}$ (RITC) and silica nanoparticles was demonstrated to be $50 \mathrm{~nm}$ (Additional file 1: Fig. S1), with MNPs@SiO ${ }_{2}$ (RITC) being reported to have a zeta potential of -40 to $-30 \mathrm{mV}[13,20]$. A previous study using inductively coupled plasma atomic emission spectrometry showed that approximately $10^{5}$ particles of MNPs@ $\mathrm{SiO}_{2}$ (RITC) per cell were internalised in MCF-7 breast cancer cells [13]. We determined the dosage used in the present study by treating HEK293 cells with MNPs@ $\mathrm{SiO}_{2}$ (RITC) at concentrations ranging from 0.01 to $2.0 \mu \mathrm{g} / \mu \mathrm{L}$ for $12 \mathrm{~h}$ and calculating their uptake efficiencies [21]. We accordingly found that the optimal concentration of MNPs@SiO ${ }_{2}$ (RITC) for in vitro use was $0.1 \mu \mathrm{g} /$ $\mu \mathrm{L}$; this concentration had been previously used for MRI contrast without any reported toxicological effects in human cord blood-derived mesenchymal stem cells [43]. In addition, any disturbances in gene expression and metabolic profiles of treated cells at this concentration were similar to those observed in control cells [21]. We further observed that the uptake efficiency of MNPs@ $\mathrm{SiO}_{2}(\mathrm{RITC})$ plateaued at $1.0 \mu \mathrm{g} / \mu \mathrm{L}$. Therefore, we used a low dose of $0.1 \mu \mathrm{g} / \mu \mathrm{L}$ and high dose of $1.0 \mu \mathrm{g} / \mu \mathrm{L}$ in the present study.

\section{MNPs@SiO $(\mathrm{RITC})$-induced lipid peroxidation decreases cell membrane fluidity}

We determined the optimal concentrations of MNPs@ $\mathrm{SiO}_{2}$ (RITC) for cell labelling, as well as the cellular uptake of nanoparticles during a $12 \mathrm{~h}$-incubation to be 0.1 and $1.0 \mu \mathrm{g} / \mu \mathrm{L}$, respectively, based on our previous studies using a fluorescence assessment method [4, 21]. We found that the viability of cells treated with $1.0 \mu \mathrm{g} /$ $\mu \mathrm{L}$ MNPs@SiO ${ }_{2}$ (RITC) was similar to that of cells with or without treatment with bare silica nanoparticles (NPs) of the same size (50 $\mathrm{nm}$ in diameter) (Additional file 1: Fig. S2), consistent with previous reports [4, 21].

We analysed the changes in lipid peroxidation and membrane fluidity in treated HEK293 cells using total internal reflection fluorescence microscopy (TIRFM). We furthermore investigated the changes in cell membrane fluidity after treatment with $\mathrm{MNPs@SiO}_{2}$ (RITC) by measuring the values of 6-dodecanoyl-2-dimethylaminonaphthalene (laurdan) generalised polarization (GP) using TIRFM (Fig. 1a). We accordingly noted that the number of high-GP areas on the cell surface, corresponding to rigid domains, increased on treatment with MNPs@SiO $($ RITC); in particular, abundantly distributed regions of MNPs@SiO ${ }_{2}$ (RITC) were found to be primarily colocalised with high GP-distributed regions at a GP scale of -1.0 to 1.0 (Fig. 1b, Additional file 1: Fig. S3). We subtracted the GP frequency distribution values of treated cells from the corresponding values of untreated control cells to obtain frequency difference curves (Fig. 1c) and total mean GP values (Fig. 1d). We observed a similar trend in the relative levels of peroxidised lipids (Fig. 1e).

A previous study revealed that $\mathrm{MNPs@SiO} \mathrm{S}_{2}$ (RITC) induced the generation of intracellular ROS via mitochondria dysfunction in HEK293 cells. In particular, generation of ROS in cells treated for $12 \mathrm{~h}$ was attributed to the shell of MNPs@SiO 2 (RITC) and silica nanoparticles (silica NPs) rather than the cobalt ferrite core [4, 21]. Thus, to determine the MNPs@SiO $2($ RITC) treatmentinduced generation of intracellular ROS, we performed $2^{\prime}, 7^{\prime}$-dichlorodihydrofluorescein diacetate staining in HEK293 cells treated with MNPs@SiO $2($ RITC) and silica NPs. We observed that the level of intracellular ROS was increased by over $50 \%$ upon treatment with both $1.0 \mu \mathrm{g} / \mu \mathrm{L}$ MNPs@SiO ${ }_{2}(\mathrm{RITC})$ and silica NPs compared with that in untreated control and $0.1 \mu \mathrm{g} / \mu \mathrm{L}$ MNPs@ $\mathrm{SiO}_{2}$ (RITC)- and silica NPs-treated cells (Additional file 1: Fig. S4). In addition, we did not observe any significant difference in the treatment with $1.0 \mu \mathrm{g} / \mu \mathrm{L}$ MNPs@ $\mathrm{SiO}_{2}$ (RITC) and silica NPs, in line with previous reports $[4,21]$. These results indicated that the rigid regions in the plasma membrane were increased through lipid peroxidation induced by ROS generated from the shell of $\mathrm{MNPs@SiO} 2$ (RITC).

\section{Treatment with MNPs@SiO ${ }_{2}(\mathrm{RITC})$ decreased cell aspect ratio and spread area but increased traction force}

As membrane fluidity is known to be closely related to cell morphology and focal adhesion [44, 45], we investigated whether a decrease in $\mathrm{MNPs@SiO}{ }_{2}$ (RITC)-mediated membrane fluidity would also affect cell morphology and focal adhesion. We evaluated the effects of MNPs@ $\mathrm{SiO}_{2}(\mathrm{RITC})$ on cell polarity as local cell contraction is tightly associated with these activities along with changes in focal adhesion [46]. Moreover, we measured the cell aspect ratio. We analysed images of cells and submicron pillars at $12 \mathrm{~h}$ after cell seeding (Fig. 2a, b). We found that the aspect ratio of cells treated with $0.1 \mu \mathrm{g} / \mu \mathrm{L}$ MNPs@ $\mathrm{SiO}_{2}$ (RITC) did not significantly differ from that of untreated control cells. However, the ratio of cells treated with $1.0 \mu \mathrm{g} / \mu \mathrm{L} \mathrm{MNPs} @ \mathrm{SiO}_{2}(\mathrm{RITC})$ was shown to be significantly smaller than that of untreated control cells (Fig. 2c).

We then used pillar deflection in the magnified images to measure pillar displacement (Fig. 2d) and calculate traction force (Fig. 2e, f). To calculate pillar traction force, the displacement of each pillar was multiplied with the pillar bending stiffness [31]. In particular, we noted that $1.0 \mu \mathrm{g} / \mu \mathrm{L}$ MNPs@SiO${ }_{2}(\mathrm{RITC})$-treated cells showed an increase in pillar displacement $(351 \pm 65 \mathrm{~nm}$; mean $\pm \mathrm{SD}$ ), which was significantly higher than that in untreated control cells $(216 \pm 46 \mathrm{~nm})$. The average $(8.5 \pm 2 \mathrm{nN})$ and total $(1112 \pm 197 \mathrm{nN})$ traction forces 
in $1.0 \mu \mathrm{g} / \mu \mathrm{L}$ MNPs@SiO${ }_{2}$ (RITC)-treated cells were significantly higher than those ( $5.2 \pm 1$ and $855 \pm 172 \mathrm{nN})$ in untreated control cells, indicating that cell traction force was affected by $1.0 \mu \mathrm{g} / \mu \mathrm{L}$ MNPs@SiO${ }_{2}$ (RITC). Taken together, the increase in cell traction force was suggested to have been caused by the MNPs@SiO ${ }_{2}$ (RITC) treatment-induced reduction in cell polarity and spread area.

Treatment with MNPs@SiO $(\mathrm{RITC})$ - impaired cell movement We previously analysed the effect of treatment with MNPs@SiO ${ }_{2}$ (RITC) on the migratory activity of human bone marrow-derived mesenchymal stem cells (hBMMSCs). Using conventional assays, such as scratch and invasion assays, we observed an impairment in the migratory activity of hBM-MSCs [42]. To evaluate the biophysical changes related to biological functions of HEK293, we analysed the effect of 0.1 or $1.0 \mu \mathrm{g} /$ $\mu \mathrm{L}$ MNPs@SiO ${ }_{2}$ (RITC) on the movement of HEK293 cells using conventional assays. Accordingly, using the scratch assay, we did not observe any difference in the migratory activity between $\mathrm{MNPs@SiO}$ (RITC)-treated HEK293 cells and untreated control cells (Fig. 3a). Similarly, no difference was observed between the invasion ability of MNPs@SiO${ }_{2}$ (RITC)-treated HEK293 cells and untreated control cells analysed using the transwell invasion assay (Fig. 3b).

However, it should be mentioned that the aforementioned results of the scratch and invasion assays did not exclude the cell growth effect and treatment with growth-arrest agents, such as mitomycin $\mathrm{C}$, as these assays are known to be highly toxic to HEK293 cells [47]. Thus, we analysed the movement of individual cells by tracking cells on pillars for $24 \mathrm{~h}$ after treatment with MNPs@SiO ${ }_{2}$ (RITC) for $12 \mathrm{~h}$ on a dish (Additional files 2, 3, 4: Movie S1, Movie S2, and Movie S3). We remarked that the distances travelled by cells were decreased to a significantly greater extent in MNPs@ $\mathrm{SiO}_{2}(\mathrm{RITC})$-treated HEK293 cells compared with untreated control cells at both 6 and $24 \mathrm{~h}$ (Fig. 3c). In addition, we obtained similar results for movement speeds at $6 \mathrm{~h}$ and $24 \mathrm{~h}$ (Fig. 3d).

\section{Treatment with MNPs@SiO ${ }_{2}(\mathrm{RITC})$ decreased intracellular level of ATP}

To evaluate the changes in the intracellular level of ATP in MNPs@SiO 2 (RITC)-treated cells, HEK293 cells were treated with MNPs@SiO 2 (RITC) at concentrations ranging from 0 to $2.0 \mu \mathrm{g} / \mu \mathrm{L}$ for 6,12 , and $24 \mathrm{~h}$ (Fig. 4). We found that intracellular levels of ATP were decreased in a dose-dependent manner in MNPs@ $\mathrm{SiO}_{2}(\mathrm{RITC})$-treated cells, starting from the $0.13 \mu \mathrm{g} / \mu \mathrm{L}$ dose. Moreover, we observed that the decrement pattern was similar for 6,12 , and $24 \mathrm{~h}$ treatments.

\section{Metabotranscriptomic network of MNPs@ $\mathrm{SiO}_{2}$ (RITC)-treated HEK293 cells}

To analyse the dispersion phenomena of MNPs@ $\mathrm{SiO}_{2}(\mathrm{RITC})$-treated cells, we constructed a coexpression network of genes and metabolites using a transcriptome generated from microarray analysis and the metabolome derived from amino acid and organic acid profiling through the Ingenuity Pathway Analysis (IPA, http://www.ingenuity.com) [21]. Microarray expression analysis showed that the levels of 21 and 31 genes associated with lipid peroxidation and focal adhesion formation, respectively, were altered in MNPs@ $\mathrm{SiO}_{2}$ (RITC)-treated cells (Fig. 5a, b). Using a threefold cut-off only to determine changes in the transcriptomic network, we detected more pronounced changes in $1.0 \mu \mathrm{g} / \mu \mathrm{L}$ MNPs@SiO $\mathrm{Si}_{2}(\mathrm{RITC})$-treated cells compared with $0.1 \mu \mathrm{g} / \mu \mathrm{L}$ MNPs@SiO ${ }_{2}(\mathrm{RITC})$-treated and control cells; these changes were related to cell movement (Fig. 5c, Additional file 1: Fig. S5). In silico prediction of the network revealed activation of lipid peroxidation, as well as suppression of focal adhesion and cell movement in $1.0 \mu \mathrm{g} / \mu \mathrm{L}$ MNPs@SiO 2 (RITC)-treated HEK293 cells (Fig. 5d).

Although transcriptomics provided comprehensive information regarding $\mathrm{MNPs@SiO}{ }_{2}$ (RITC)-treated cells, the data obtained were only qualitative. Thus, for a network-based evaluation, we used a combination of transcriptome and metabolome networks, termed the metabotranscriptomic network, through substitution of amino acid and organic acid profiles (cut-off $\pm 20 \%$ change), as described in our previous report [21]. In the

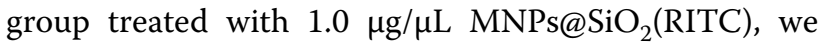
found that the amino acid, organic acid, and free fatty acid profiles showed increased levels of tyrosine, pyruvic acid, glutamic acid, lysine, and lignoceric acid; in contrast, we observed decreased levels of cysteine, asparagine, 3-hydroxybutyric acid, glutamine, serine, aspartic acid, oxaloacetic acid, glycine, and acetoacetic acid [37]. This combined network provided more reliable information than the transcriptomic network alone, allowing also the detection of more pronounced changes in $1.0 \mu \mathrm{g} / \mu \mathrm{L}$

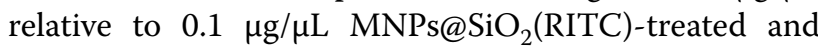
control cells (Fig. 6a, Additional file 1: Fig. S6, Table S1). In silico prediction of the integrated network also revealed a similar trend to that observed in the transcriptome network (Additional file 1: Fig. S7).

We subsequently quantified the expression level of genes associated with the network using semi-quantitative reverse transcription PCR (Fig. 6b) and quantitative 
a

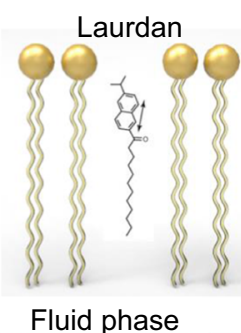

Fluid phase
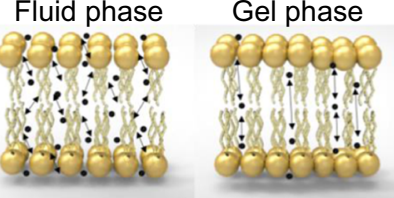

Low GP value High GP value b
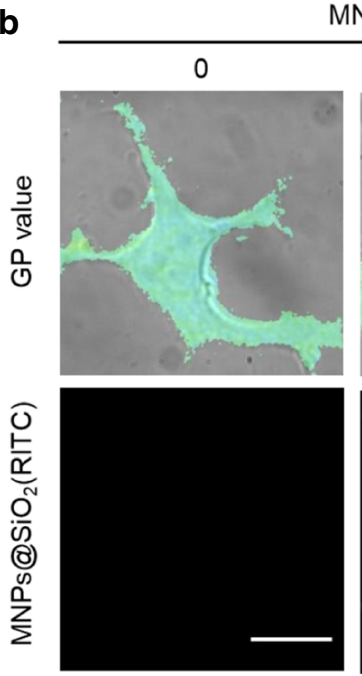

MNPs@SiO $2(\mathrm{RITC})(\mu \mathrm{g} / \mu \mathrm{l})$

0.1
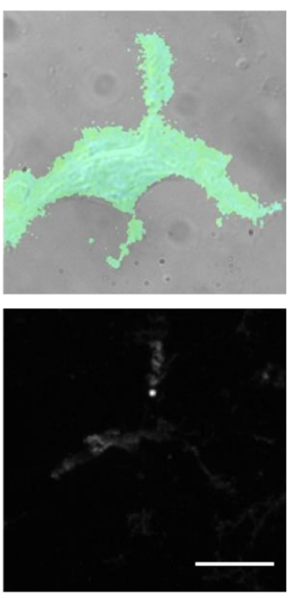

1.0
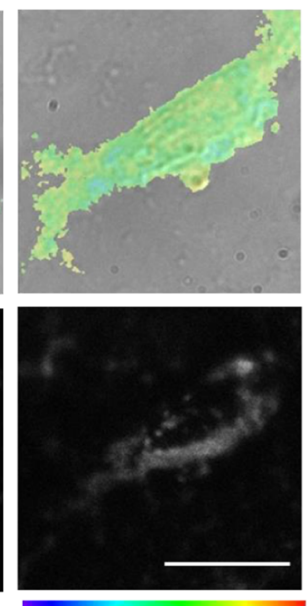

-1.0 GP distributions 1.0
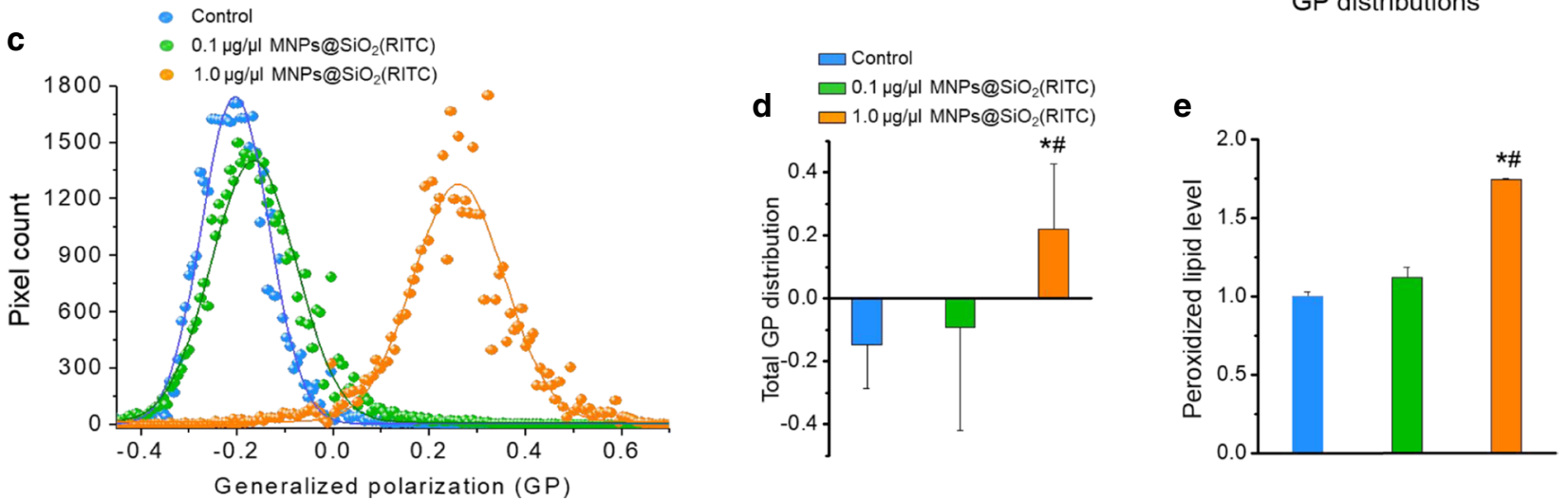

Fig. 1 Laurdan GP images and GP frequency distributions of MNPs@SiO ${ }_{2}(\mathrm{RITC})$-treated HEK293 cells. a Schematic representation of laurdan usage for measuring the GP value of membranes. b Merged DIC and psuedo-coloured GP images (upper panel) of HEK293 cells. MNPs@SiO (RITC) distributions are shown in each lower panel. GP distributions ranged from -1.0 to 1.0. Scale bar $=2.5 \mu \mathrm{m}$. c GP frequency distributions of cells. GP values of each pixel are represented as dots and were fitted to Gaussian distributions. $\mathbf{d}$ Total GP values. Data represent the mean \pm SD of 3 independent experiments $(\mathrm{N}=10)$. e Evaluation of peroxidised lipids using ferrous thiocyanate. The intensity of ferrous thiocyanate alone was used as the blank. Data represent the mean \pm SD of 3 independent experiments. ${ }^{*} p<0.05$ vs untreated control, ${ }^{*} p<0.05$ compared between 0.1 and $1.0 \mu \mathrm{g} / \mu \mathrm{L}$ MNPs@SiO ${ }_{2}(\mathrm{RITC})$-treated cells

(q) PCR (Fig. 6c). In particular, we found that expression levels of superoxide dismutase 2 (SOD2) and LIM zinc finger domain-containing 1 (LIMS1) were increased, whereas those of NCK adaptor protein 1 (NCK1) and complement C3a receptor 1 (C3AR1) were decreased in the $1.0 \mu \mathrm{g} / \mu \mathrm{L} \mathrm{MNPs} @ \mathrm{SiO}_{2}(\mathrm{RITC})$-treated cells relative to those in untreated control cells.

\section{Discussion}

The present study demonstrated the effects of nanoparticles on the biophysical properties of cells. In addition, functional analysis using the metabotranscriptomics approach allowed us to deduce inter-connective relationships between genes and metabolites associated with lipid peroxidation, focal adhesion, and cell movement in MNPs@SiO ${ }_{2}$ (RITC)-treated cells.

We observed that the $1.0 \mu \mathrm{g} / \mu \mathrm{L}$ MNPs@SiO ${ }_{2}$ (RITC)treated cells exhibited markedly increased levels of lipid peroxidation compared with the $0.1 \mu \mathrm{g} / \mu \mathrm{L}$ MNPs@ $\mathrm{SiO}_{2}$ (RITC)-treated cells and untreated control. These results indicated that exposure of cells to $1.0 \mu \mathrm{g} / \mu \mathrm{L}$ MNPs@SiO ${ }_{2}$ (RITC) might impair certain biological functions due to the production of ROS and lipid peroxidation. This was consistent with the finding that oxidative stress induces lipid peroxidation, which is often observed in disease states, such as aging, sickle-cell disease, 




malaria, and diabetes [48-50]. It was also consistent with the decrease in the deformability of hBM-MSCs over time owing to the generation of intracellular ROS and lipid peroxidation, which was shown to lead to decreased membrane fluidity and deteriorated cell quality [41]. Moreover, we previously showed that ROS-distributed regions distinctly co-localised with $\mathrm{MNPs@SiO}_{2}$ (RITC)distributed regions in cells [21]; hence, we assumed that

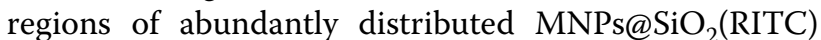
might be primarily co-localised with high GP-distributed regions along with lipid peroxidation, thus distinguishing damaged membrane regions from intracellular regions. Thus, our results suggested that exposure of cells to $1.0 \mu \mathrm{g} / \mu \mathrm{L}$ MNPs@SiO ${ }_{2}$ (RITC) could potentially impair the biological functions of exposed cells by increasing their membrane rigidity.

Nanoparticle-induced cell membrane damage is reportedly caused through direct interactions between membrane lipids and nanoparticles [51]. Further, silica and gold nanoparticles are known to penetrate cell membranes [52, 53]. In particular, 50-nm NPs were demonstrated to be likely internalised through endocytic pathways as nanoparticles $>10 \mathrm{~nm}$ were found to be coated directly with the plasma membrane and be internalized via clathrin- and caveolae-mediated endocytic pathways $[54,55]$. In this study, the altered gene expression of the clathrin-mediated endocytic pathway was reported to significantly alter the internalization of 


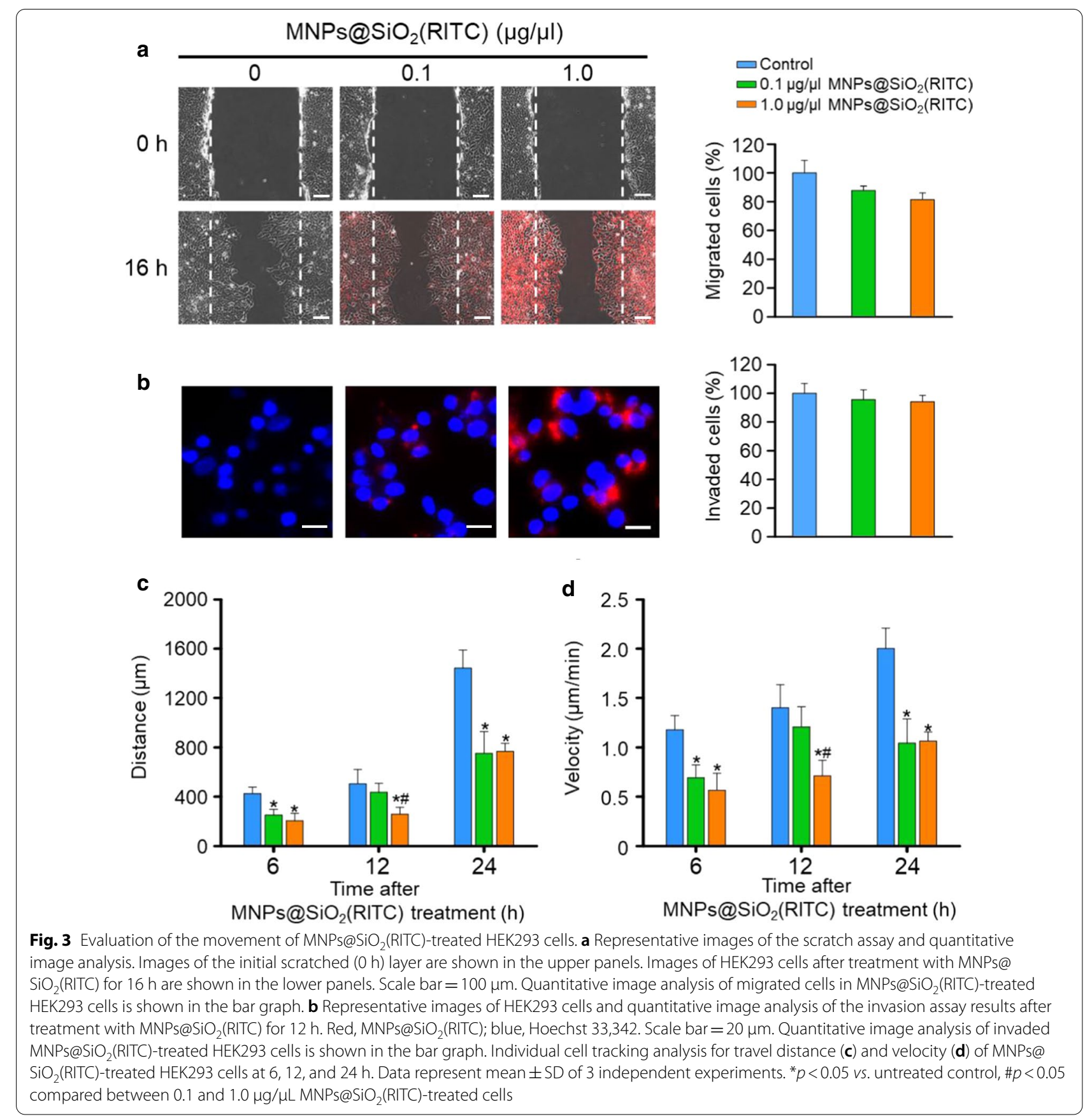

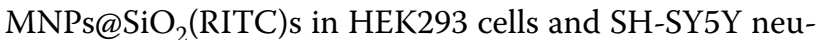
roblastoma cells [4]. Thus, we proposed that MNPs@ $\mathrm{SiO}_{2}$ (RITC) enter cells through endocytosis; this might constitute one reason for the observed decreased membrane fluidity because membrane tension regulates membrane deformation or changes in cell shape (e.g., endocytosis, exocytosis, cytokinesis, and cell motility) [56].
As the membrane and cytoskeleton are known to be tightly associated with phosphoinositides, the status of cell membranes has been highly linked to the regulation of the cytoskeleton [57, 58]. Nanoparticle-induced lipid peroxidation has been reported to alter cell morphology and membrane roughness in human lymphocytes [59]. We accordingly found that the cell aspect ratio and cell spread area were decreased in MNPs@ 

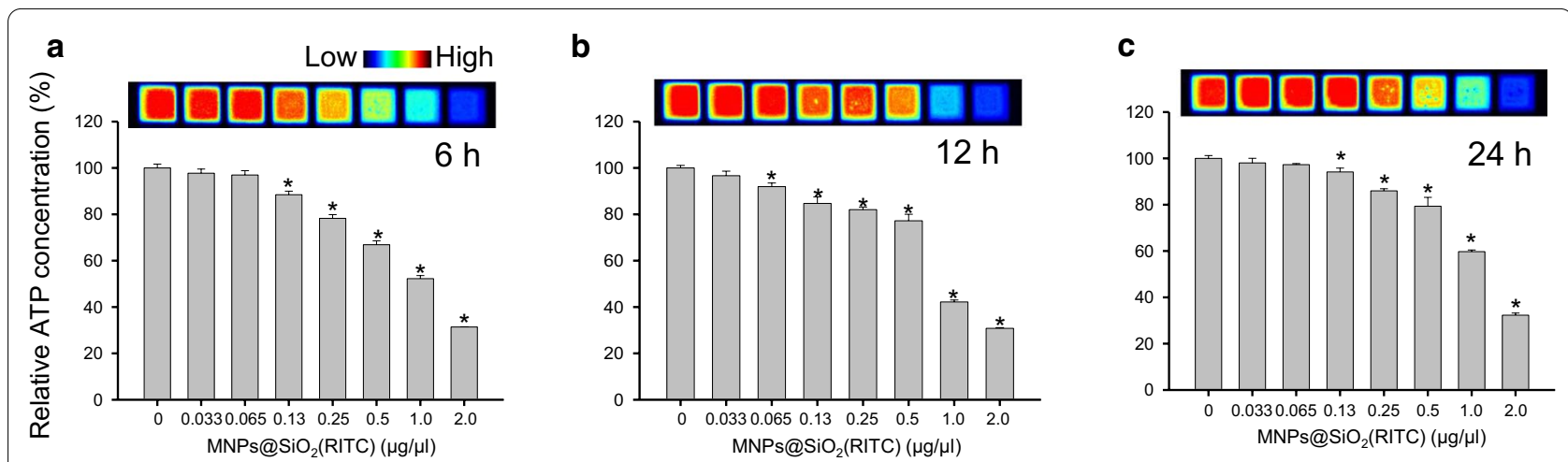

Fig. 4 Evaluation of intracellular level of ATP in MNPs@SiO 2 (RITC)-treated HEK293 cells. HEK293 cells were treated with 0 to $2.0 \mu \mathrm{g} / \mu \mathrm{L}$ MNPs@ $\mathrm{SiO}_{2}$ (RITC) for $\mathbf{a} 6, \mathbf{b} 12$, and $\mathbf{c} 24 \mathrm{~h}$, and the intracellular ATP level was evaluated. Luminance was captured and expressed as a pseudo-colour scale image. Data represent mean \pm SD of 3 independent experiments. ${ }^{*} p<0.05 \mathrm{vs}$. untreated control, ${ }^{\sharp} p<0.05$ compared between $0.1 \mathrm{and} 1.0 \mu \mathrm{g} / \mu \mathrm{L}$ MNPs@SiO 2 (RITC) -treated cells

$\mathrm{SiO}_{2}(\mathrm{RITC})$-treated cells, which exhibited a round morphology, suggesting that focal adhesion was impaired owing to the imbalance between adhesion and tension caused by treatment with MNPs@SiO 2 (RITC) treatment.

Nanoparticles have also been shown to increase traction force but inhibit cellular migration [60]. Traction force is known to be primarily regulated by phosphorylation of myosin II through the assembly (dephosphorylated myosin) and disassembly (phosphorylated myosin) of the myosin light chain (also termed the myosin head) and actin filaments, with these processes obtaining energy from the hydrolysis of ATP [61, 62]. Our previous study showed that the intracellular level of ATP in $1.0 \mu \mathrm{g} /$ $\mu \mathrm{L}$ MNPs@SiO ${ }_{2}$ (RITC)-treated cells was decreased to approximately $50 \%$ due to mitochondrial damage [21]. In the present study, we observed that treatment with MNPs@SiO ${ }_{2}$ (RITC) decreased the intracellular levels of ATP in dose- and time-dependent manners. This might have been one of the factors responsible for the observed increment in the total traction force and reduction in cell movement activity.

There were limitations in interpreting the actual phenotype obtained in the transcriptome network associated with lipid peroxidation, focal adhesion, and cell movement. Thus, we combined datasets providing information on the interactions between differentially expressed genes and altered metabolites, and generated a metabotranscriptomic network. In particular, the network showed that the expression levels of $S O D 2$, which is tightly associated with oxidative stress [63], and LIMS1, which is an important molecule in the linkage between actin and integrin for the formation of focal adhesion [64], were increased, whereas the levels of NCK1, an upstream regulator in the formation of actin-rich protrusions in the plasma membrane [65], and C3AR1, which is reduced in oxidative conditions $[66,67]$, were decreased in $1.0 \mu \mathrm{g} / \mu \mathrm{L} \mathrm{MNPs} @ \mathrm{SiO}_{2}(\mathrm{RITC})$-treated cells relative to those in untreated controls. Thus, the convergence of the metabolic profiles and transcriptome disturbances allowed interpretation of the changes in the movement of $\mathrm{MNPs@SiO}$ (RITC)-treated cells.

Dose justification is determined based on uptake (labelling) efficiency, and using a fluorescence assessment method, we previously reported that the plateau of uptake (labelling) occurred at $1.0 \mu \mathrm{g} / \mu \mathrm{L}$ MNPs@ $\mathrm{SiO}_{2}$ (RITC)-treated HEK293 cells [21]. Moreover, with respect to toxicity, reduction in the cell viability of MNPs@SiO ${ }_{2}$ (RITC) treated HEK293 cells was not identified. However, changes in ATP levels were observed with respect to NP concentration, that is, an approximately 50\% decrement in the level of ATP in $1.0 \mu \mathrm{g} / \mu \mathrm{L}$ MNPs@ $\mathrm{SiO}_{2}$ (RITC)-treated HEK293 cells exhibiting a plateau uptake, whereas an approximately $5 \%$ decrement in the level of ATP in $0.1 \mu \mathrm{g} / \mu \mathrm{L}$ MNPs@SiO${ }_{2}$ (RITC)-treated HEK293 cells with an adequate uptake.

The effects of MNPs@SiO ${ }_{2}$ (RITC) and silica NPs on HEK293 cells were similar with respect to cell viability and ROS generation. In addition, cellular localization of MNPs@SiO ${ }_{2}$ (RITC) and silica NPs indicated that both types of NPs were accumulated in lysosomes (Additional file 1: Fig. S8). Consistent with our previous reports, we postulated that the effects of $\mathrm{MNPs@SiO} \mathrm{Si}_{2}$ (RITC) were exerted by silica, which is a peripheral part of the MNPs@SiO ${ }_{2}$ (RITC) $[4,21,42]$.

The decrease in moving speed was recovered in control and MNPs@SiO 2 (RITC)-treated HEK293 cells in a timedependent manner. This could be explained by a couple of possibilities. One possibility is that cells adapted to the altered conditions. Another possibility is that the MNPs@SiO 2 (RITC)-induced decrement in moving speed 


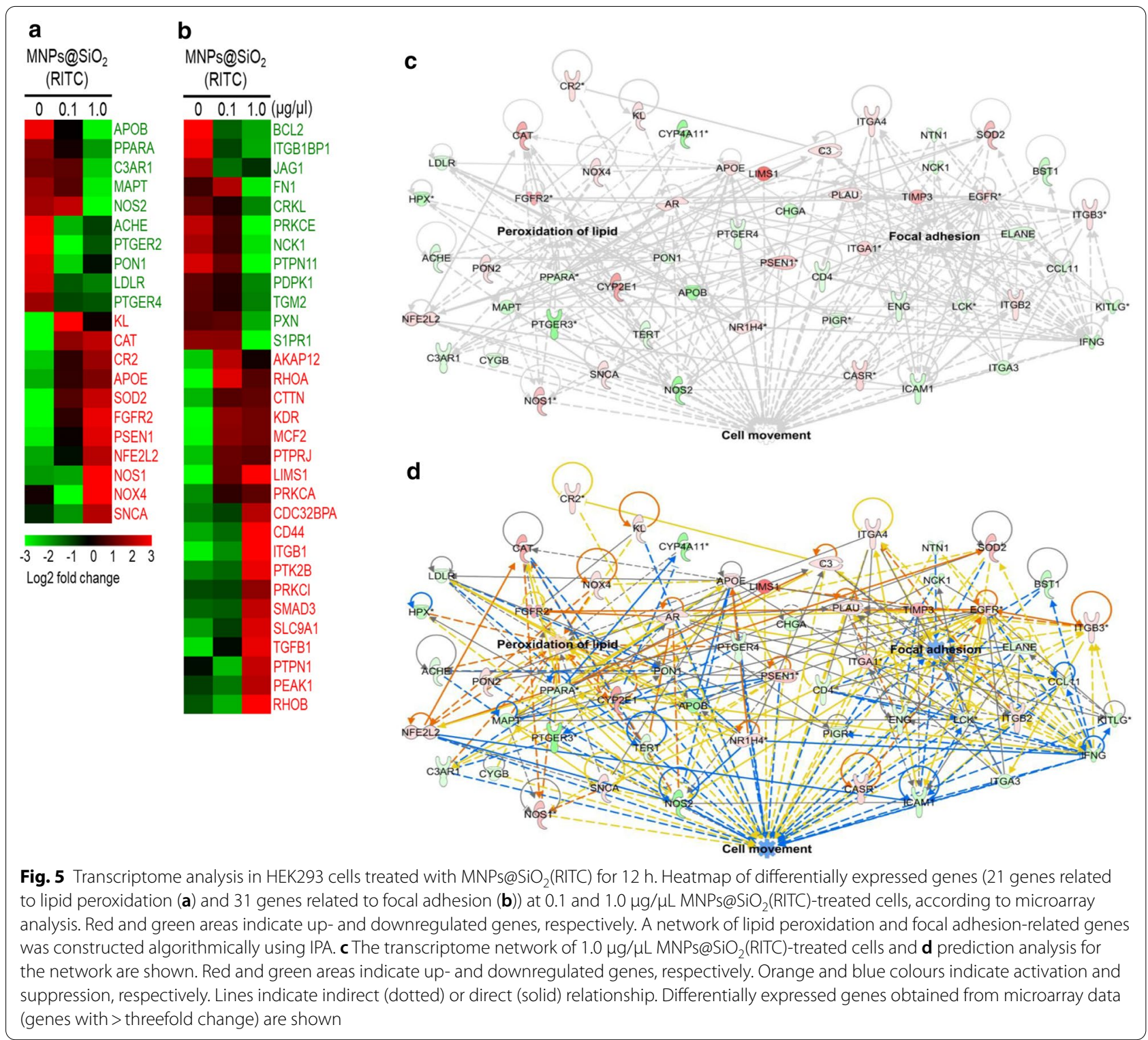

changed phases in a time-dependent manner [6 $\mathrm{h}$ (acute phase), $12 \mathrm{~h}$ (intermediate phase), and $24 \mathrm{~h}$ (chronic phase)]. As shown in the changes in the concentration of ATP (Fig. 4), the decreased levels of ATP were recovered, but not fully. These possibilities might have been reflected in the moving speed of $\mathrm{MNPs@SiO}_{2}(\mathrm{RITC})-$ treated HEK293 cells.

The possibility of the dye and cobalt ferrite leaching out of MNPs@SiO 2 (RITC) and exerting toxic effects in cells exposed to these nanoparticles for a long time has been a main concern. For instance, the dye signal of MNPs@ $\mathrm{SiO}_{2}$ (RITC) was reduced by approximately 90 and $40 \%$ in human cord blood-derived mesenchymal stem cells during their third and seventh passages, respectively. These observed reductions might have been due to the dilution effect generated by cell proliferation [19]. As there have been reports that treatment with MNPs@ $\mathrm{SiO}_{2}$ (RITC) did not cause any significant loss and measurable toxicological effects in HEK293 cells for $7 \mathrm{~d}$ and in a mouse model for $4 \mathrm{wk}$, respectively, it was assumed that the highly toxic cobalt ferrite substance did not leach out of the core of MNPs@SiO 2 (RITC) [4, 18, 21]. Based on these reports, we assumed that our MNPs@SiO ${ }_{2}$ (RITC) nanoparticles were also stable enough to allow the discernment of subtle toxicity in cells exposed to MNPs@ $\mathrm{SiO}_{2}(\mathrm{RITC})$ for a long time. 


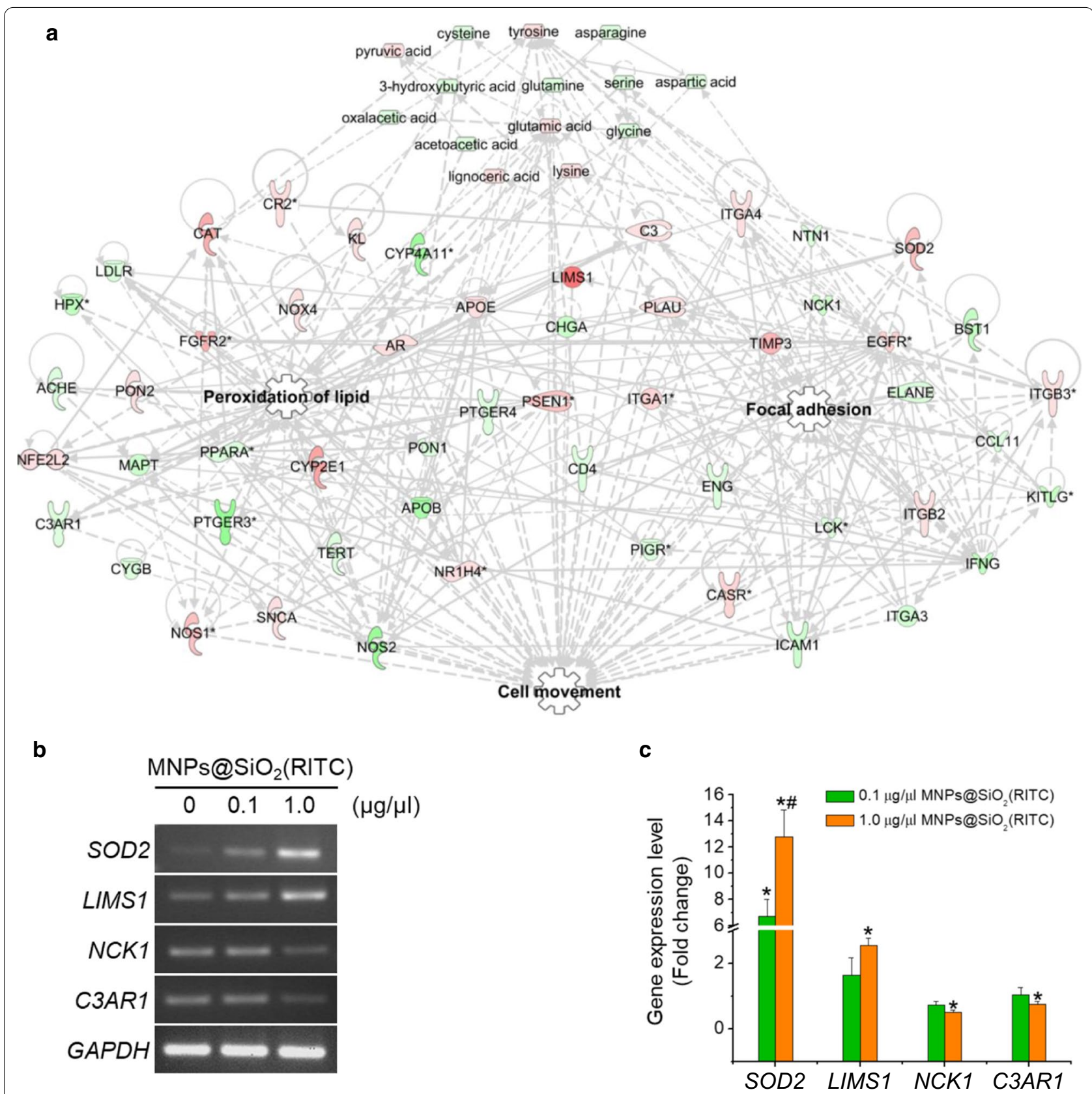

Fig. 6 Metabotranscriptomic analysis of the microarray and metabolite profile of MNPs@SiO $(\mathrm{RITC}$ )-treated cells. a Lipid peroxidation and focal adhesion-related genes and metabolite networks were algorithmically constructed using IPA. Red and green areas indicate up-and downregulated genes, respectively. Lines indicate indirect (dotted) or direct (solid) relationship. Differentially expressed genes obtained from microarray data ( $>$ threefold change) and disturbances in the metabolic profile (>20\% change) are shown. Quantitative evaluation of the metabotranscriptomic network-related genes by $\mathbf{b}$ semi-quantitative reverse transcription (RT)-PCR and $\mathbf{c}$ quantitative real-time PCR. Cells were treated with 0.1 and $1.0 \mu \mathrm{g} / \mu \mathrm{L}$ MNPs@SiO $\mathrm{S}_{2}$ (RITC) for $12 \mathrm{~h}$. RT-PCR and qPCR were performed using gene-specific primer pairs for SOD2, LIMS1, NCK1, and C3AR1. GAPDH was used as the internal control. PCR products were normalised relative to the levels of internal control. Data represent the mean \pm SD of 3 independent experiments. ${ }^{*} p<0.05$ vs untreated control. Transcriptome and metabolome data are reproduced from our previous study, Copyright () 2019 Springer Nature [37]

\section{Conclusions}

In conclusion, our results demonstrated a reduction in membrane fluidity, abnormal focal adhesion, and decrement in cell movement upon treatment with a

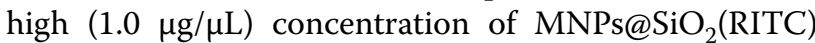
nanoparticles. Our findings indicated that nanoparticles 
should be used at the lowest possible dosage in therapeutic or diagnostic applications to prevent potential nanotoxicity. Our comprehensive approach of toxicological evaluation will aid the future assessment of nanoparticle sensitivity and associated potential toxicity. Moreover, our findings on nanotoxicity will be beneficial in terms of the development of safe nanoparticles for biomedical applications.

\section{Materials and methods}

\section{Measurement of membrane fluidity}

Changes in membrane fluidity were measured using laurdan, a fluorescent dye that exhibits a $60-\mathrm{nm}$ spectral shift from disordered to ordered bilayer phases, and an in-house combined differential interference contrasttotal internal reflection fluorescence microscopy experimental system (DIC-TIRFM) [41, 68]. The procedure was based on a well-described protocol [41, 69, 70]. Briefly, cells were seeded on cover slips (no. 1 thickness, 0.13$0.16 \mathrm{~mm}$ ) and treated with 0.1 and $1.0 \mu \mathrm{g} / \mu \mathrm{L}$ MNPs@ $\mathrm{SiO}_{2}$ (RITC) for $12 \mathrm{~h}$. For staining with laurdan, cells were incubated with medium containing $10 \mu \mathrm{M}$ laurdan at $37^{\circ} \mathrm{C}$ and $5 \% \mathrm{CO}_{2}$ for $2 \mathrm{~h}$. Cells were washed twice with phosphate buffered saline (PBS) and fixed with fixation buffer (Cytofix; BD, San Jose, CA, USA). Cover slips containing cells were mounted onto other cover slips (no. 1 thickness, $0.13-0.16 \mathrm{~mm}$ ) using mounting medium (Prolong gold antifade; Molecular Probes, Eugene, OR, USA). Cell morphological changes, laurdan fluorescence, and MNPs@SiO 2 (RITC) distribution were observed using an oil-type $100 \times$ objective lens (Olympus UPLFL $100 \times / 1.3$ N.A., W.D. $0.1 \mathrm{~mm}$, Tokyo, Japan) and a CCD camera (QuantEM 512SC, Photometrics, Tucson, AZ, USA). Laurdan was excited at $405 \mathrm{~nm}$, and emission fluorescence was detected with $420 \mathrm{~nm}$ and $473 \mathrm{~nm}$ bandpass filters (resolution: $\pm 5 \mathrm{~nm}$ ). As a parameter of membrane fluidity, GP $\left[\left(\right.\right.$ Intensity ${ }_{420} \mathrm{~nm}$ - Intensity $\left.y_{473} \mathrm{~nm}\right) /($ Intensity $_{420 \mathrm{~nm}}+$ Intensity $_{473 \mathrm{~nm}}$ )] was calculated and pseudocoloured; GP images merged with DIC images were generated using the Image J software $(\mathrm{NIH}$, Bethesda, MD, USA) [71]. Gaussian distributions were generated using the nonlinear fitting algorithm in Sigma plot 10.0 (Systat Software Inc., San Jose, CA, USA).

\section{Microfabrication of submicron elastomeric pillar array}

Photolithography was used to fabricate a silicon wafer mould with a series of holes [72]. To make the pillars, polydimethylsiloxane (PDMS) was mixed in a 10:1 ratio with its curing agent (Sylgard 184; Dow Corning, Midland, MI, USA) and vacuumed for $15 \mathrm{~min}$; the mould was then spin-coated with PDMS at 1,000 RPM for $1 \mathrm{~min}$ and again vacuumed for $30 \mathrm{~min}$ to remove bubbles. The mould with PDMS was cured at $80{ }^{\circ} \mathrm{C}$ for $3 \mathrm{~h}$.
The pillar array was manufactured using this method. Each pillar was $900 \mathrm{~nm}$ in diameter $(D), 1 \mu \mathrm{m}$ in height $(L)$, and $1.8 \mu \mathrm{m}$ in centre-to-centre distance. To calculate the bending stiffness $(k)$ of the pillar, the Euler-Bernoulli beam theory was applied [31]:

$$
k=\frac{3}{64} \pi E \frac{D^{4}}{L^{3}}
$$

where $E$ is the Young's modulus $(2 \mathrm{MPa})$ of the cured PDMS. Using this equation, the $k$ of the pillar was calculated to be $24.2 \mathrm{nN} / \mu \mathrm{m}$.

\section{Measurement of cell aspect ratio}

The cell aspect ratio was measured by representing the area of the entire cell with a comparable elliptical shape using ImageJ (NIH); the division from the major axis of the ellipse to the minor axis was then taken as the cell aspect ratio.

\section{Measurement of traction force}

Pillar images were acquired using a fluorescence microscope (Deltavision, GE Healthcare, Chicago, IL, USA) and a camera (CoolSNAP $\mathrm{HQ}^{2}$, Photometrics) at $37^{\circ} \mathrm{C}$ and $5 \%$ humidity with a live cell chamber at $1 \mathrm{~Hz}$. The location of each pillar in each frame was determined using the pillar tracking plugin (PillarTracker 1.1.3 version) for ImageJ. In the pillar reconstruction algorithm, the PillarTracker works to establish the exact grid of the pillar array, thereby allowing users to automatically detect and track the pillar locations. Throughout this study, pillars that had no contact with cells were used as reference pillars. To account for stage drift, the average displacement of reference pillars was deducted from the displacement data of pillars deflected by cells. To avoid the unwanted displacement of pillars by MNPs@ $\mathrm{SiO}_{2}(\mathrm{RITC}), \quad \mathrm{MNPs} @ \mathrm{SiO}_{2}(\mathrm{RITC})$-treated cells were washed five times using PBS (Sigma-Aldrich, St. Louis, MO, USA) before seeding onto the pillar array. The displacement of each pillar was multiplied with its bending stiffness to calculate the traction force $(F)$.

\section{Scratch assay}

HEK293 cells were seeded and cultured to $100 \%$ confluence in 6-well plates. Cell monolayers were scratched using 200- $\mu \mathrm{L}$ micropipette tips. Media were replaced with serum-free media, and HEK293 cells were treated with MNPs@SiO $\mathrm{S}_{2}$ (RITC) for 16 h. Images of scratched areas were captured both before treatment $(0 \mathrm{~h})$ and after treatment (16 h) using an Axio Vert $200 \mathrm{M}$ fluorescence microscope (Zeiss, Jena, Germany). Migration activity was quantified by counting the number of migrated cells from the initial scratch. 


\section{Transwell invasion assay}

Cell invasion activity was analysed using an $8-\mu \mathrm{m}$ pore size Transwell polycarbonate membrane (Corning, CA, USA), as in a previous study [73]. The upper side of the insert was coated with Matrigel (1:10 dilution in $0.01 \mathrm{M}$ Tris $\mathrm{pH} 8.0,0.7 \% \mathrm{NaCl}$ ) for $2 \mathrm{~h}$ at $37^{\circ} \mathrm{C}$. Subsequently, $1 \times 10^{3}$ HEK293 cells were treated with MNPs@ $\mathrm{SiO}_{2}$ (RITC) in serum-free medium for $12 \mathrm{~h}$ and seeded onto the insert. Then, $10 \%$ FBS-containing medium was added to the lower chamber as a chemoattractant. Cells were incubated for $12 \mathrm{~h}$ at $37{ }^{\circ} \mathrm{C}$ to allow invasion. The upper side of the membrane was washed with a cotton swab, and invaded cells on the lower side of the membrane were fixed in Cytofix buffer (BD, San Jose, CA, USA) and stained with $10 \mu \mathrm{g} / \mu \mathrm{L}$ Hoechst 33342 for 15 min at $25{ }^{\circ} \mathrm{C}$. Images were acquired using an Axio Vert $200 \mathrm{M}$ fluorescence microscope (Zeiss, Jena, Germany). The number of invaded cells was counted using the Image J software (NIH).

\section{Cell tracking}

PDMS pillars were coated with fibronectin for $1 \mathrm{~h}$ before seeding of cells. Cells were seeded at a density of 3000 cells per sample and tracked every $5 \mathrm{~min}$ for $6 \mathrm{~h}$ on a $\mathrm{JuLi}^{\mathrm{TM}} \mathrm{Br}$ live cell movie analyser (NanoEntek, Inc., Seoul, Korea). Finally, cell movement speed was calculated by tracking cells using the ImageJ software (NIH).

\section{Metabotranscriptomic data analysis}

Differences in the gene expression of cells were examined using the Affymetrix system (ISTECH, South Korea) in conjunction with the Human U133 Plus $2.050 \mathrm{~K}$ microarray, which contains 54,675 probes. Differences in the data distribution were analysed using the GenPlex 3.0 software [21], with the probe signals being quantilenormalised. Amino acid and organic acid profiles were imported from previously reported data [21]. Biological pathways and functions were identified using the Ingenuity pathway analysis web-based bioinformatics software (IPA; Ingenuity Systems, Redwood City, CA, USA). Three-fold change in gene expression and $20 \%$ change in metabolites were used as cut-offs to generate datasets of significantly altered genes and metabolites.

\section{Statistical analysis and error correction}

Results were analysed by one-way analysis of variance (ANOVA) with Bonferroni's multiple-comparison test using the IBM-SPSS software (IBM Corp., Armonk, NY, USA). $p<0.05$ was considered statistically significant. In the experiments using micropillars, errors in the pillar deflections were corrected by reducing the average pillar deflection of pillars outside the cell.

\section{Supplementary Information}

The online version contains supplementary material available at https://doi. org/10.1186/s12951-020-00765-5.

Additional file 1: Table S1. Ingenuity Pathway Analysis-based profiles of

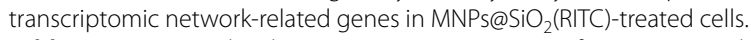
Table S2. RT-PCR and real-time PCR primer sequences for genes encoding transcriptomic network-related genes. Figure S1. Determination of size and homogeneity for MNPs@SiO ${ }_{2}$ (RITC) and silica NPs using transmission

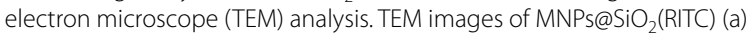
and silica NPs (b). Scale bar $=50 \mathrm{~nm}$. Figure S2. Evaluation of cytotoxicity in silica NPs and MNPs@SiO 2 (RITC) treated HEK293 cells. HEK293 cells were treated with silica NPs and MNPs@SiO ${ }_{2}$ (RITC) for $12 \mathrm{~h}$. The changes in cell viability were evaluated with MTS. Data represent mean \pm SD of three independent experiments. N.S: Not significant. Figure S3. Low magnification laurdan GP images. Merged DIC and TIRFM images (upper panel) of HEK293 cells. Distributions of MNPs@SiO ${ }_{2}(\mathrm{RITC})$ are shown in each lower panel. GP distributions ranged from -1.0 to 1.0. Scale bar $=2.5$ $\mu \mathrm{m}$. Figure S4. ROS generation in silica NPs and MNPs@SiO 2 (RITC)-treated cells. Evaluation of intracellular ROS generation using DCFH-DA after $12 \mathrm{~h}$ silica NPs and MNPs@SiO 2 (RITC) treatment in HEK293 cells. The intensity of non-oxidised DCFH-DA was used as a blank. Data represent mean \pm SD of three independent experiments. ${ }^{*} p<0.05$ vs non-treated control, ${ }^{\#} \mathrm{p}<0.05$ compared between 0.1 and $1.0 \mu \mathrm{g} / \mu$ l of NPs-treated cells. N.S: Not significant. Figure S5. Transcriptomic analysis of microarray in HEK293 cells treated with MNPs@SiO 2 (RITC) for 12 h. Network of lipid peroxidation and focal adhesion related genes was constructed algorithmically by IPA.

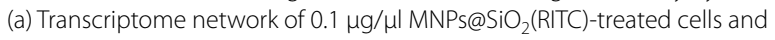
(b) prediction analysis for the network. Red and green areas indicate upand downregulated genes, respectively. Orange and blue colours indicate activation and suppression. The lines indicate indirect (dotted) or direct (solid) relationship. Differentially expressed genes obtained from microarray data (genes with > 3-fold change) are shown. Figure S6. Metabotranscriptomic analysis of microarray and metabolite profiles in cells treated with $0.1 \mu \mathrm{g} / \mu \mathrm{l}$ MNPs@SiO 2 (RITC) for $12 \mathrm{~h}$. (a) Lipid peroxidation and focal adhesion related genes and metabolites network were constructed algorithmically by IPA in $0.1 \mu \mathrm{g} / \mu \mathrm{l}$ MNPs@SiO ${ }_{2}$ (RITC)-treated HEK293 cells and (b) prediction analysis for the network. Red and green areas indicate upand downregulated genes, respectively. Orange and blue colours indicate activation and suppression, respectively. The lines indicate indirect (dotted) or direct (solid) relationship. Differentially expressed genes obtained from microarray data ( $>3$-fold change) and disturbances in metabolic profile (> 20\% change) are shown. Figure $\mathbf{S 7}$. Metabotranscriptomic analysis of microarray and metabolite profile in cells treated with $1.0 \mu \mathrm{g} /$ $\mu \mathrm{MNNS} @ \mathrm{SiO}_{2}$ (RITC) for $12 \mathrm{~h}$. Lipid peroxidation and focal adhesion related genes and metabolites network were constructed algorithmically by IPA in $1.0 \mathrm{\mu g} / \mathrm{\mu l}$ MNPs@SiO ${ }_{2}(\mathrm{RITC})$-treated HEK293 cells. Red and green areas indicate up- and downregulated genes, respectively. Orange and blue colours indicate activation and suppression, respectively. The lines indicate indirect (dotted) or direct (solid) relationship. Differentially expressed genes obtained from microarray data ( $>3$-fold change) and disturbances in metabolic profile (> 20\% change) are shown. Figure S8. Z-stack analysis for NPs treated HEK293 cells. The cells were treated with silica NPs and MNPs@SiO ${ }_{2}$ (RITC) for $12 \mathrm{~h}$. The locations of NPs were analysed with $z$-stack mode of confocal microscopy. Nucleus, blue; NPs, red; ubiquitin, green; lysosome, violet. Scale bar $=10 \mu \mathrm{m}$.

Additional file 2: Movie S1. Tracking movement of non-treated control HEK293 cells on pillars for $24 \mathrm{~h}$.

Additional file 3: Movie S2. Tracking movement of $0.1 \mu \mathrm{g} / \mu \mathrm{L}$ MNPs@ $\mathrm{SiO}_{2}$ (RITC) treated HEK293 cells on pillars for $24 \mathrm{~h}$.

Additional file 4: Movie S3.Tracking movement of $1.0 \mu \mathrm{g} / \mu \mathrm{L}$ MNPs@ $\mathrm{SiO}_{2}(\mathrm{RITC})$ treated HEK293 cells on pillars for $24 \mathrm{~h}$.

\section{Acknowledgments}

The authors would like to thank the Ajou Core-Facility Center, Sinae Ahn, and Sun Young Che for technical assistance and cell image analysis. 


\section{Authors' contributions}

THS, AAK, SP, and GL conceived and designed the experiments. THS and AAK performed the experiments and analysed the data. SL and SHK manufactured the lab-built microscopy system. DYL and DHK performed cell experiments of NPs. BM and SB helped with experimental design, and data analysis. THS, AAK, SP, and GL drafted the paper. All the authors read and approved the final manuscript.

\section{Funding}

This work was supported by research grants (2018R1D1A1B07049494), (2018R1A2B2002066), and BioNano Health-Guard Research Center grants (H-GUARD_2018M3A6B2057299), (2020R1C1C1008366), (2020R1A4A4079722), (2020M3E5D9080661), and (2016M3C7A1904392) through the National Research Foundation funded by the Ministry of Science and ICT (MSIP) of Korea.

\section{Ethics approval and consent to participate}

Not applicable.

\section{Consent for publication}

Not applicable.

\section{Competing interests}

The authors declare that they have no competing interests.

\section{Author details}

${ }^{1}$ Department of Physiology, Ajou University School of Medicine, Suwon 16499, Republic of Korea. ${ }^{2}$ School of Mechanical Engineering, Sungkyunkwan University, Suwon 16419, Republic of Korea. ${ }^{3}$ Department of Applied Chemistry and Institute of Natural Sciences, Kyung Hee University, Yongin-si 17104, Republic of Korea. ${ }^{4}$ Department of Molecular Science and Technology, Ajou University, Suwon 16499, Republic of Korea.

Received: 22 October 2020 Accepted: 28 December 2020

Published online: 11 January 2021

\section{References}

1. Xia T, Kovochich M, Liong M, Madler L, Gilbert B, Shi H, Yeh Jl, Zink Jl, Nel AE. Comparison of the mechanism of toxicity of zinc oxide and cerium oxide nanoparticles based on dissolution and oxidative stress properties. ACS Nano. 2008;2:2121-34.

2. Nel AE, Madler L, Velegol D, Xia T, Hoek EM, Somasundaran P, Klaessig F, Castranova $\mathrm{V}$, Thompson M. Understanding biophysicochemical interactions at the nano-bio interface. Nat Mater. 2009:8:543-57.

3. Krug HF, Wick P. Nanotoxicology: an interdisciplinary challenge. Angew Chem Int Ed Engl. 2011:50:1260-78.

4. Phukan G, Shin TH, Shim JS, Paik MJ, Lee JK, Choi S, Kim YM, Kang SH, Kim HS, Kang Y, et al. Silica-coated magnetic nanoparticles impair proteasome activity and increase the formation of cytoplasmic inclusion bodies in vitro. Sci Rep. 2016;6:29095.

5. Nel A, Xia T, Madler L, Li N. Toxic potential of materials at the nanolevel. Science. 2006;311:622-7.

6. Auffan M, Rose J, Bottero JY, Lowry GV, Jolivet JP, Wiesner MR. Towards a definition of inorganic nanoparticles from an environmental, health and safety perspective. Nat Nanotechnol. 2009:4:634-41.

7. Liu R, Liu HH, Ji Z, Chang CH, Xia T, Nel AE, Cohen Y. Evaluation of toxicity ranking for metal oxide nanoparticles via an in vitro dosimetry model. ACS Nano. 2015;9:9303-13.

8. Akbarzadeh A, Samiei M, Davaran S. Magnetic nanoparticles: preparation, physical properties, and applications in biomedicine. Nanoscale Res Lett. 2012;7:144

9. Belanova AA, Gavalas N, Makarenko YM, Belousova MM, Soldatov AV, Zolotukhin PV. Physicochemical properties of magnetic nanoparticles: implications for biomedical applications in vitro and in vivo. Oncol Res Treat. 2018;41:139-43.

10. Dowaidar M, Abdelhamid HN, Hallbrink M, Freimann K, Kurrikoff K, Zou X, Langel U. Magnetic nanoparticle assisted self-assembly of cell penetrating peptides-oligonucleotides complexes for gene delivery. Sci Rep. 2017;7:9159

11. Zhou Y, Tang Z, Shi C, Shi S, Qian Z, Zhou S. Polyethylenimine functionalized magnetic nanoparticles as a potential non-viral vector for gene delivery. J Mater Sci Mater Med. 2012;23:2697-708.

12. Uthaman S, Lee SJ, Cherukula K, Cho CS, Park IK. Polysaccharide-coated magnetic nanoparticles for imaging and gene therapy. Biomed Res Int. 2015;2015:959175.

13. Yoon TJ, Kim JS, Kim BG, Yu KN, Cho MH, Lee JK. Multifunctional nanoparticles possessing a "magnetic motor effect" for drug or gene delivery. Angew Chem Int Ed Engl. 2005;44:1068-71.

14. Ding YF, Li S, Liang L, Huang Q, Yuwen L, Yang W, Wang R, Wang LH. Highly biocompatible chlorin E6-loaded chitosan nanoparticles for improved photodynamic cancer therapy. ACS Appl Mater Interfaces. 2018;10:9980-7.

15. Abdelhamid HN, Wu HF. Multifunctional graphene magnetic nanosheet decorated with chitosan for highly sensitive detection of pathogenic bacteria. J Mater Chem B. 2013:1:3950-61.

16. Nasser Abdelhamid H, Wu BS, Wu HF. Graphene coated silica applied for high ionization matrix assisted laser desorption/ionization mass spectrometry: a novel approach for environmental and biomolecule analysis. Talanta. 2014;126:27-37.

17. Gopal J, Abdelhamid HN, Hua PY, Wu HF. Chitosan nanomagnets for effective extraction and sensitive mass spectrometric detection of pathogenic bacterial endotoxin from human urine. J Mater Chem B. 2013;1:2463-75.

18. Kim JS, Yoon TJ, Yu KN, Kim BG, Park SJ, Kim HW, Lee KH, Park SB, Lee JK, $\mathrm{Cho} \mathrm{MH}$. Toxicity and tissue distribution of magnetic nanoparticles in mice. Toxicol Sci. 2006:89:338-47.

19. Park KS, Tae J, Choi B, Kim YS, Moon C, Kim SH, Lee HS, Kim J, Kim J, Park J, et al. Characterization, in vitro cytotoxicity assessment, and in vivo visualization of multimodal, RITC-labeled, silica-coated magnetic nanoparticles for labeling human cord blood-derived mesenchymal stem cells. Nanomedicine. 2010;6:263-76.

20. Beck GR Jr, Ha SW, Camalier CE, Yamaguchi M, Li Y, Lee JK, Weitzmann MN Bioactive silica-based nanoparticles stimulate bone-forming osteoblasts, suppress bone-resorbing osteoclasts, and enhance bone mineral density in vivo. Nanomedicine. 2012:8:793-803.

21. Shim W, Paik MJ, Nguyen DT, Lee JK, Lee Y, Kim JH, Shin EH, Kang JS, Jung HS, Choi S, et al. Analysis of changes in gene expression and metabolic profiles induced by silica-coated magnetic nanoparticles. ACS Nano. 2012;6:7665-80.

22. Shin TH, Lee DY, Lee HS, Park HJ, Jin MS, Paik MJ, Manavalan B, Mo JS, Lee $\mathrm{G}$. Integration of metabolomics and transcriptomics in nanotoxicity studies. BMB Rep. 2018;51:14-20.

23. Girotti AW. Lipid hydroperoxide generation, turnover, and effector action in biological systems. J Lipid Res. 1998:39:1529-42.

24. Cazzola R, Rondanelli M, Russo-Volpe S, Ferrari E, Cestaro B. Decreased membrane fluidity and altered susceptibility to peroxidation and lipid composition in overweight and obese female erythrocytes. J Lipid Res. 2004:45:1846-51.

25. de la Haba C, Palacio JR, Martinez P, Morros A. Effect of oxidative stress on plasma membrane fluidity of THP-1 induced macrophages. Biochim Biophys Acta. 2013;1828:357-64.

26. Soenen SJ, Nuytten N, De Meyer SF, De Smedt SC, De Cuyper M. High intracellular iron oxide nanoparticle concentrations affect cellular cytoskeleton and focal adhesion kinase-mediated signaling. Small. 2010:6:832-42.

27. Hall A. Rho GTPases and the actin cytoskeleton. Science. 1998:279:509-14.

28. Kuhner S, Fischer S. Structural mechanism of the ATP-induced dissociation of rigor myosin from actin. Proc Natl Acad Sci U S A. 2011;108:7793-8

29. Tan JL, Tien J, Pirone DM, Gray DS, Bhadriraju K, Chen CS. Cells lying on a bed of microneedles: an approach to isolate mechanical force. Proc Nat Acad Sci U S A. 2003;100:1484-9.

30. du Roure O, Saez A, Buguin A, Austin RH, Chavrier P, Silberzan P, Ladoux B. Force mapping in epithelial cell migration. Proc Natl Acad Sci U S A. $2005 \cdot 102 \cdot 2390-5$ 
31. Ghassemi S, Meacci G, Liu S, Gondarenko AA, Mathur A, Roca-Cusachs P Sheetz MP, Hone J. Cells test substrate rigidity by local contractions on submicrometer pillars. Proc Natl Acad Sci U S A. 2012;109:5328-33.

32. Evans TG. Considerations for the use of transcriptomics in identifying the "genes that matter" for environmental adaptation. J Exp Biol. 2015;218:1925-35.

33. Rehrauer H, Opitz L, Tan G, Sieverling L, Schlapbach R. Blind spots of quantitative RNA-seq: the limits for assessing abundance, differential expression, and isoform switching. BMC Bioinformatics. 2013;14:370.

34. Gibney MJ, Walsh M, Brennan L, Roche HM, German B, van Ommen B. Metabolomics in human nutrition: opportunities and challenges. Am J Clin Nutr. 2005;82:497-503.

35. Shin TH, Lee DY, Basith S, Manavalan B, Paik MJ, Rybinnik I, Mouradian MM, Ahn JH, Lee G. Metabolome changes in cerebral ischemia. Cells. 2020;9:1630.

36. Van Assche R, Broeckx V, Boonen K, Maes E, De Haes W, Schoofs L, Temmerman L. Integrating -omics: systems biology as explored through C. elegans research. J Mol Biol. 2015;427:3441-51.

37. Shin TH, Seo C, Lee DY, Ji M, Manavalan B, Basith S, Chakkarapani SK, Kang SH, Lee G, Paik MJ, Park CB. Silica-coated magnetic nanoparticles induce glucose metabolic dysfunction in vitro via the generation of reactive oxygen species. Arch Toxicol. 2019;93:1201-12.

38. Ketebo AA, Shin TH, Jun M, Lee G, Park S. Effect of silica-coated magnetic nanoparticles on rigidity sensing of human embryonic kidney cells. Journal of Nanobiotechnology. 2020;18:170.

39. Zhang $Q, X u H$, Zheng S, Su M, Wang J. Genotoxicity of mesoporous silica nanoparticles in human embryonic kidney 293 cells. Drug Test Anal. 2015;7:787-96.

40. Wang F, Gao F, Lan M, Yuan H, Huang Y, Liu J. Oxidative stress contributes to silica nanoparticle-induced cytotoxicity in human embryonic kidney cells. Toxicol In Vitro. 2009;23:808-15.

41. Shin TH, Lee S, Choi KR, Lee DY, Kim Y, Paik MJ, Seo C, Kang S, Jin MS, Yoo $\mathrm{TH}$, et al. Quality and freshness of human bone marrow-derived mesenchymal stem cells decrease over time after trypsinization and storage in phosphate-buffered saline. Sci Rep. 2017;7:1106.

42. Shin TH, Lee DY, Ketebo AA, Lee S, Manavalan B, Basith S, Ahn C, Kang SH, Park S, Lee G. Silica-coated magnetic nanoparticles decrease human bone marrow-derived mesenchymal stem cell migratory activity by reducing membrane fluidity and impairing focal adhesion. Nanomaterials (Basel). 2019:9:1475

43. Park KS, Tae J, Choi B, Kim YS, Moon C, Kim SH, Lee HS, Kim J, Park J, Lee $\mathrm{JH}$, et al. Characterization, in vitro cytotoxicity assessment, and in vivo visualization of multimodal, RITC-labeled, silica-coated magnetic nanoparticles for labeling human cord blood-derived mesenchymal stem cells. Nanomed Nanotechnol Biol Med. 2010;6:263-76.

44. Gaus K, Le Lay S, Balasubramanian N, Schwartz MA. Integrin-mediated adhesion regulates membrane order. J Cell Biol. 2006:174:725-34.

45. Sun M, Northup N, Marga F, Huber T, Byfield FJ, Levitan I, Forgacs G. The effect of cellular cholesterol on membrane-cytoskeleton adhesion. J Cell Sci. 2007;120:2223-31.

46. Notbohm J, Banerjee S, Utuje KJC, Gweon B, Jang H, Park Y, Shin J, Butler $J P$, Fredberg JJ, Marchetti MC. Cellular contraction and polarization drive collective cellular motion. Biophys J. 2016;110:2729-38.

47. Hsieh JH, Huang R, Lin JA, Sedykh A, Zhao J, Tice RR, Paules RS, Xia M, Auerbach SS. Real-time cell toxicity profiling of Tox21 10K compounds reveals cytotoxicity dependent toxicity pathway linkage. PLoS ONE. 2017:12:e0177902.

48. Chien S. Red cell deformability and its relevance to blood flow. Annu Rev Physiol. 1987:49:177-92.

49. Mohanty JG, Nagababu E, Rifkind JM. Red blood cell oxidative stress impairs oxygen delivery and induces red blood cell aging. Front Physiol. 2014;5:84

50. Hierso R, Waltz X, Mora P, Romana M, Lemonne N, Connes P, Hardy-Dessources MD. Effects of oxidative stress on red blood cell rheology in sickle cell patients. Br J Haematol. 2014;166:601-6.

51. Van Lehn RC, Ricci M, Silva PH, Andreozzi P, Reguera J, Voitchovsky K, Stellacci F, Alexander-Katz A. Lipid tail protrusions mediate the insertion of nanoparticles into model cell membranes. Nat Commun. 2014;5:4482.

52. Lin J, Zhang H, Chen Z, Zheng Y. Penetration of lipid membranes by gold nanoparticles: insights into cellular uptake, cytotoxicity, and their relationship. ACS Nano. 2010:4:5421-9.
53. Mu Q, Hondow NS, Krzeminski L, Brown AP, Jeuken LJ, Routledge MN. Mechanism of cellular uptake of genotoxic silica nanoparticles. Part Fibre Toxicol. 2012;9:29.

54. Oh N, Park JH. Endocytosis and exocytosis of nanoparticles in mammalian cells. Int J Nanomedicine. 2014;9(Suppl 1):51-63.

55. Wang Z, Tiruppathi C, Minshall RD, Malik AB. Size and dynamics of caveolae studied using nanoparticles in living endothelial cells. ACS Nano. 2009;3:4110-6

56. Nambiar R, McConnell RE, Tyska MJ. Control of cell membrane tension by myosin-I. Proc Natl Acad Sci U S A. 2009;106:11972-7.

57. Saarikangas J, Zhao H, Lappalainen P. Regulation of the actin cytoskeleton-plasma membrane interplay by phosphoinositides. Physiol Rev. 2010;90:259-89.

58. Geissler KJ, Jung MJ, Riecken LB, Sperka T, Cui Y, Schacke S, Merkel U, Markwart R, Rubio I, Than ME, et al. Regulation of Son of sevenless by the membrane-actin linker protein ezrin. Proc Natl Acad Sci U S A. 2013;110:20587-92.

59. Zhornik EV, Baranova LA, Drozd ES, Sudas MS, Chau NH, Buu NQ, Dung TT, Chizhik SA, Volotovskii ID. Silver nanoparticles induce lipid peroxidation and morphological changes in human lymphocytes surface. Biofizika. 2014;59:466-73.

60. Tay CY, Cai P, Setyawati MI, Fang W, Tan LP, Hong CH, Chen X, Leong DT. Nanoparticles strengthen intracellular tension and retard cellular migration. Nano Lett. 2014;14:83-8.

61. Kasza KE, Farrell DL, Zallen JA. Spatiotemporal control of epithelial remodeling by regulated myosin phosphorylation. Proc Natl Acad Sci U S A. 2014:111:11732-7.

62. Gerthoffer WT, Schaafsma D, Sharma P, Ghavami S, Halayko AJ. Motility, survival, and proliferation. Compr Physiol. 2012;2:255-81.

63. Mohanty JG, Nagababu E, Friedman JS, Rifkind JM. SOD2 deficiency in hematopoietic cells in mice results in reduced red blood cell deformability and increased heme degradation. Exp Hematol. 2013;41:316-21.

64. Humphrey JD, Dufresne ER, Schwartz MA. Mechanotransduction and extracellular matrix homeostasis. Nat Rev Mol Cell Biol. 2014;15:802-12.

65. Yamaguchi H, Lorenz M, Kempiak S, Sarmiento C, Coniglio S, Symons M, Segall J, Eddy R, Miki H, Takenawa T, Condeelis J. Molecular mechanisms of invadopodium formation: the role of the N-WASP-Arp2/3 complex pathway and cofilin. J Cell Biol. 2005;168:441-52.

66. Zhao W, Zhao T, Chen Y, Qu Y, Gerling IC, Sun Y. Modification of oxidative stress on gene expression profiling in the rat infarcted heart. Mol Cell Biochem. 2013;379:243-53.

67. Rutar M, Natoli R, Albarracin R, Valter K, Provis J. 670-nm light treatment reduces complement propagation following retinal degeneration. J Neuroinflammation. 2012;9:257.

68. Lee S, Cho NP, Kim JD, Jung H, Kang SH. An ultra-sensitive nanoarray chip based on single-molecule sandwich immunoassay and TIRFM for protein detection in biologic fluids. Analyst. 2009;134:933-8.

69. Owen DM, Rentero C, Magenau A, Abu-Siniyeh A, Gaus K. Quantitative imaging of membrane lipid order in cells and organisms. Nat Protoc. 2012;7:24-35.

70. Schneckenburger H, Stock K, Strauss WS, Eickholz J, Sailer R. Time-gated total internal reflection fluorescence spectroscopy (TG-TIRFS): application to the membrane marker laurdan. J Microsc. 2003;211:30-6.

71. Hansen JS, Helix-Nielsen C. An epifluorescence microscopy method for generalized polarization imaging. Biochem Biophys Res Commun. 2011;415:686-90

72. Tan JL, Liu W, Nelson CM, Raghavan S, Chen CS. Simple approach to micropattern cells on common culture substrates by tuning substrate wettability. Tissue Eng. 2004;10:865-72.

73. Lee DY, Jin MS, Manavalan B, Kim HK, Song JH, Shin TH, Lee G. Bidirectional transcriptome analysis of rat bone marrow-derived mesenchymal stem cells and activated microglia in an in vitro coculture system. Stem Cells Int. 2018;2018:6126413.

\section{Publisher's Note}

Springer Nature remains neutral with regard to jurisdictional claims in published maps and institutional affiliations. 